\title{
Mobile Payment Sebagai Sisitem Pembayaran Masa Depan
}

\author{
Mubaddilah Rafa'al \\ Universitas Nuku
}

\begin{abstract}
Abstrak
Keterlibatan ponsel dalam bidang ini dikenal sebagai mobile payment. Mobile Payment adalah pembayaran barang atau jasa menggunakan perangkat bergerak seperti telepon genggam atau PDA yang telah memiliki kemampuan NFC. Determinism teknologi dihubungkan dengan Mobile payment bahwa perkembangan teknologi komunikasi dalam hal ini adalah mobile payment mempengaruhi ketergantungan cara manusia dalam melakukan kegiatan transaksi terhadap pembelian yang dilakukan, dimana dengan meletakan chip dan perangkat lunak/software kedalam ponsel untuk mempermudah perdagangan secara elektronik. Teknologi terbentuk untuk menyesuaikan kebutuhan manusia akan kegiatan melakukan pembayaran secara aman dan mudah serta fleksibel dari telefon atau ponsel konsumen. semakin majunya teknologi sekarang ini, dan sudah mulai banyak bermunculan pembayaran elektronik ini sangat memungkinkan 5 tahun atau 10 tahun yang akan datang karena untuk lebih memudahkan kita tentunya dalam hal bertransaksi melaui mobile payment.
\end{abstract}

\section{Teknologi Mobile Payment}

Perkembangan penggunaan telepon seluler di masyarakat Indonesia yang pesat saat ini memberi peluang bagi penggunaan mobile payment yang lebih luas. Namun, penggunaan teknologi mobile payment konvensional yang ada saat ini terbentur oleh penggunaan perangkat telepon seluler dengan teknologi yang sangat beragam, mulai dari perangkat telepon seluler low-end yang masih menggunakan layar monokromatis dan fitur yang terbatas kepada layanan untuk melakukan panggilan telepon dan mengirimkan pesan singkat, hingga telepon seluler dengan teknologi yang sangat lengkap menyerupai suatu komputer.

Bertambahnya jumlah pengguna telepon seluler (ponsel) menuntut adanya inovasi teknologi yang mampu memudahkan pengguna dalam menjalankan aktivitasnya, termasuk transaksi perdagangan yang makin marak. Solusi baru kini coba dikembangkan dalam melakukan fungsi penggantian cara transaksi untuk menunjang aktivitas bisnis. Solusi baru ini melibatkan teknologi ponsel sebagai sarana untuk bertransaksi.

Ponsel ini akan diposisikan sebagai tools yang bekerja menggantikan uang fisik atau kartu kredit. Hasilnya, kini ponsel sudah bisa dimanfaatkan untuk transaksi jual-beli, baik micropayment serta macropayment. Keterlibatan ponsel dalam bidang ini dikenal sebagai mobile payment. 
Menurut McKitterick (2003), beberapa atribut penting mendasari mobile payment diantaranya adalah aktor yang terlibat, karakterisasi dari mobile payment, skenario mobile payment dan operasi yang terlibat dalam mobile payment. Mobile Payment adalah pembayaran barang atau jasa menggunakan perangkat bergerak seperti telepon genggam atau PDA yang telah memiliki kemampuan NFC. Ada banyak jenis barang dan jasa yang dapat dibeli dengan mobile payment misalnya : musik, video, ringtone, game online, buku, majalah, tiket, dll.

Ada 4 Model Utama Mobile Payment :

\section{- Premium SMS based transactional payments}

adalah request pembayaran tagihan via sms ke nomor/kode tertentu dan tagihan akan dipotong dari pulsa telepon. Contoh nya : pembelian ringtones, wallpaper, musik, dll.

\section{- Direct Mobile Billing}

adalah moda pembayaran terhadap transaksi yang dilakukan dengan menggunakan mobile account, dimana mobile account memiliki PIN dan One Time Password.

- Mobile Web Payments (WAP)

adalah request pembayaran tagihan dengan menggunakan WAP (Wireless Application Protocol) pada telepon genggam dan tagihan dibebankan ke billing telepon (Direct Operator Billing). Penggunaan mobile payment yang simple dapat menggunakan Credit Card/Kartu Kredit.

\section{- Contactless NFC (Near Field Communication)}

adalah pola pembayaran dengan menggunakan perangkat mobile yang memiliki aplikasi NFC (Near Field Communication) dimana tagihan akan dipotong dari kartu prabayar, atau ditagihkan ke billing telepon, atau akun bank secara langsung.

\section{Pengelompokan Karakteristik Mobile Payment}

Menurut McKitterick (2003), pembayaran secara mobile dapat dikategorikan kedalam beberapa kategori, seperti tipe transaksi, tipe penanganan, tipe konten, dan nilai konten. Berikut merupakan contoh dari karakteristik pembayaran yang mungkin terjadi berdasarkan kategori di atas:

\section{Berdasarkan Tipe Transaksinya:}

1. Pay Per View

Pengguna mobile membayar untuk setiap penggunaan dari layanan. Sebagai contoh, mengunduh file MP3 dan Video Klip.

2. Pay Per Event

Pengguna membayar untuk suatu layanan jasa selama rentang waktu atau nilai tertentu. 
3. Pay Per Unit

Pengguna membayar berdasarakan unit nilai yang digunakan komsumen.

Sebagai contoh, membayar setiap menit atau byte yang digunakan.

\section{Tarif Flat}

Pengguna membayar secara periodik (berlangganan) untuk akses kepada produk secara tak terbatas.

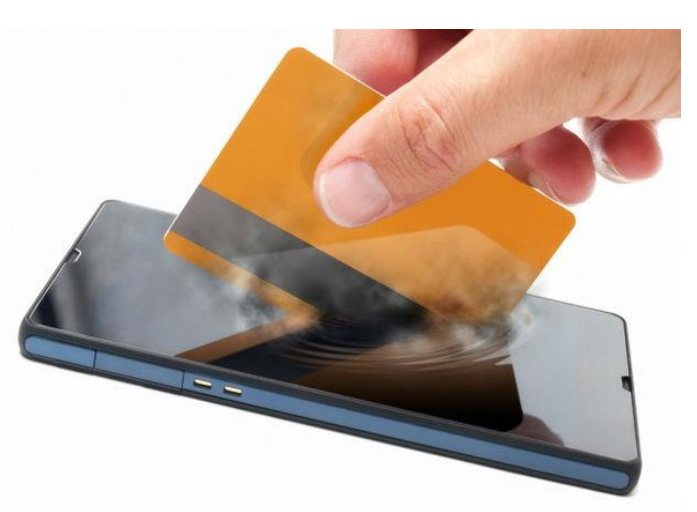




\section{Berdasarkan Tipe Penanganan Pembayaran:}

1. Pra-bayar

Pengguna membayar terlebih dahulu sejumlah uang, setelah itu apabila pengguna menggunakan layanan, maka biaya yang harus dibayar dipotong dari uang yang sudah dibayarkan sebelumnya.

2. Pasca-bayar

Pengguna akan ditagih atas penggunaan layanan setelah layanan tersebut digunakan. Umumnya ditagihkan secara periodik seperti perbulan.

\section{Tipe Konten:}

1. Barang digital

Contoh, musik yang dapat didownload atau konten video

2. Layanan digital

Seperti streaming video

3. Barang fisik

Contoh, membayar parkir dan barang belanjaan

4. Ticketing

Contoh, pembelian tiket pesawat dan kereta

\section{Nilai konten:}

1. Pembayaran mikro

Membayar produk dengan harga dibawah 10 euro.

2. Pembayaran makro

Membayar produk dengan harga di atas 10 euro.

Pembayaran seperti ini bisa merujuk pada pembayaran menggunakan pulsa ponsel atau pembayaran menggunakan ponsel yang bisa berkomunikasi dengan perangkat tujuan, memanfaatkan teknologi nirkabel seperti (NFC) Near Field Communication atau melalui SMS. Bahkan saat ini, industri perbankan kini mulai diramaikan oleh teknologi 
telekomunikasi. Melalui ponsel dan nilai rupiah yang ada di dalamnya, Anda dapat melakukan transaksi, meski belum semua tempat bisa mengaplikasikan sistem ini.

Kelanjutan e-Payment Mobile payment bisa disebut sebagai generasi kelanjutan dari e-payment yang sebagian dari kita pernah melakukannya, baik melalui kartu debet ataupun kredit. Intinya adalah sebuah transaksi yang tetap bisa dilanjutkan dengan sistem pembayaran nontunai. Biasanya mobile payment biasanya memanfaatkan teknologi m-banking (mobile banking) yang juga mendukung pola bertransaksi secara elektronik.

Uniknya, semua proses itu terkoneksi dengan rekening orang tersebut di suatu bank. Jadi, jika seseorang tak punya rekening bank atau tak merelasikan ponselnya dengan sistem bank, jelas tidak dapat melakukan $m$-banking. Selama validasi data $m$-banking sesuai dengan data di rekeningnya, seseorang dapat melakukan transaksi melalui ponsel maupun PDA. Implementasi mobile payment pertama kali dilakukan oleh operator Thailand sekitar tahun 2005. Di Korea, moda transportasi kereta api juga memanfaatkan jasa operator telekomunikasi ini untuk melakukan debet langsung, atau pengurangan nilai pulsa pelanggan, sebagai transaksi nontunai dalam pembelian tiket KA.

Hanya dengan mendekatkan ponsel ke sebuah reader, lalu done, pelanggan operator bisa menikmati perjalanan dengan kereta api. Sangat simpel! Bagaimana di Indonesia? Seberapa besar peluang mobile payment dan seberapa akuratkah? Pertanyaan ini mengemuka, karena mobile payment relatif baru di Indonesia. Tentu peluang itu sangat besar. Semua pihak bisa mendapatkan nilai lebih dari layanan operator ini. Pelanggan tentu menjadi target utama dalam layanan ini. Sejumlah merchant yang bekerja sama dengan operator dalam penyelenggaraan layanan mobile payment pun pasti mendapat keuntungan.

Perlu Edukasi Pekerjaan rumah yang mesti diperhatikan operator agar layanan ini menjadi primadona yaitu memperluas merchant-merchant atau tempat-tempat yang diajak kerja sama dalam melakukan proses mobile payment tersebut. Selain itu, diperlukan edukasi kepada masyarakat mengenai kegunaan sistem transaksi nontunai ini. Dan yang terpenting adalah payung hukum, demi kenyamanan dan keamanan proses transaksi.

Membeludaknya jumlah pengguna ponsel di negeri ini memang menjanjikan agar platform teknologi mobile payment berjalan sukses. Terlebih lagi contoh-contoh di luar negeri senantiasa sukses menjalankan pola transaksi nontunai melalui ponsel. Tentu peluang besar ini akan sia-sia jika penyelanggara berlaku pasif.

Ada tiga hal penting yang mesti dilakukan para penyelenggara agar layanan mobile payment bisa sukses. Pertama, edukasi layanan. Ini sangat penting untuk mengenalkan masyarakat kepada mobile payment. Selama ini kita sudah terbiasa menggunakan uang fisik, 
dan masih belum percaya pada transaksi virtual seperti mobile payment. Dengan edukasi intensif, maka akan muncul kepercayaan pengguna. Kedua, para penyelenggara mobile payment harus memperluas jalinan kerja sama dengan banyak pihak, terutama merchant atau bank. Tanpa dukungan jaringan yang kuat, mobile payment jelas tak akan banyak digunakan. Ketiga, teknologi dan jenis layanan. Saat ini teknologi yang digunakan mobile payment di sebagian besar negara adalah SMS. Penggunaan SMS masih dirasa kurang praktis untuk transaksi mobile payment. Kehadiran teknologi-teknologi baru tentunya diharapkan merubah persoalan ini.

\section{Konsep Teknologi dari Teori Determinism Teknologi dan Social Construction of Technology}

\section{Teori Determinism Technology}

Teori determinisme teknologi dari Marshall McLuhan. Teori ini dikemukakan untuk pertama kalinya oleh McLuhan di tahun 1962 melalui tulisannya berjudul The Guttenberg Galaxy: The Making of Typographic Man. Dasar dari teori ini mengemukakan bahwa berbagai macam cara berkomunikasi yang mengalami perubahan akan membentuk keberadaan manusia itu sendiri. Teknologi menentukan cara seorang individu berpikir dan berperialku dalam masyarakat. Pada akhirnya, teknologi akan mengarahkan manusia dalam bergerak dari satu masa teknologi ke masa teknologi lainnya. Seperti contoh, dari masyarakat yang belum mengenal huruf menuju ke masyarakat yang menggunakan perangkat komunikasi cetak, berlanjut lagi ke masyarakat yang menggunakan perangkat komunikasi elektronik.

Marshall McLuhan, sebagai dosen dari Toronto University, mengatakan bahwa the medium is the massage. Media adalah era nya massa. Hal ini artinya bahwa kita saat ini hidup di era yang unik dalam sejarah peradaban manusia, yakni era media massa. Lebih tepatnya, era media elektronik seperti saat sekarang ini. Media, pada intinya, sangat mempengaruhi cara manusia dalam merasakan, berpikir dan juga bertingkah laku. Saat ini manusia berada di era revolusi, yakni revolusi masyarakat menjadi massa, dengan adanya kehadiran media massa tersebut. Menurut McLuhan, keberadaan manusia ditentukan dengan perubahan caranya berkomunikasi. 
Bila dihubungkan dengan logika perpanjangan tubuh manusia, mesin ketik merupakan salah satu contoh perpanjangan tangan dari manusia, mobil adalah perpanjangan kaki manusia, begitu juga radio dan media cetak adalah perpanjangan mata manusia, serta teknologi komputer, televisi dan internet adalah bentuk perpanjangan pusat system syaraf manusia. Proses komunikasi dalam sebuah masyarakat berteknologi mutakhir sama sekali tak membutuhkan manusia untuk bertindak sebagai pelaku komunikasi.

Apabila determinism teknologi dihubungkan dengan Mobile payment bahwa perkembangan teknologi komunikasi dalam hal ini adalah mobile payment mempengaruhi ketergantungan cara manusia dalam melakukan kegiatan transaksi terhadap pembelian yang dilakukan, dimana dengan meletakan chip dan perangkat lunak / software kedalam ponsel untuk mempermudah perdagangan secara elektronik. Sebagai ponsel yang selalu berkembang, konsumen cenderung menggunakan inframerah, bluetooth, dan cara lain yang lebih sering digunakan untuk mengirimkan data rekening penuh untuk melakukan pembayaran secara aman dan mudah serta fleksibel dari telefon atau ponsel konsumen, sehingga seseorang tidak perlu lagi untuk datang secara fisik untuk melakukan transaksi keuangan.

Pokok dari teori McLuhan adalah determinisme teknologi. Artinya adalah bahwa perkembangan atau penemuan teknologi komunikasi yang sebenarnya mengubah kebudayaan manusia. Apabila Karl Marx berpendapat bahwa sejarah ditentukan dengan kekuatan produksi, maka McLuhan berpendapat bahwa kehadiran manusia akan ditentukan dengan perubahan mode komunikasi.

\section{Social Construction of Technology (SCOT)}

Teori Konstruksi Sosial Teknologi (juga disebut sebagai Scot) adalah teori dalam bidang studi Sains dan Teknologi. Para pendukung Scot yaitu, konstruktivis sosial berpendapat bahwa teknologi tidak mendeterminasi (menentukan) tindakan manusia, tetapi justru sebaliknya, yaitu teknologi terbentuk untuk menyesuaikan kebutuhan manusia. Mereka juga berpendapat bahwa teknologi yang digunakan tidak dapat dipahami tanpa memahami lebih dulu bagaimana sebuah teknologi yang tertanam berhubungan dengan konteks sosialnya. 
Kemampuan manusia menentukan perkembangan teknologi menjelaskan bahwa manusia memiliki kuasa terhadap teknologi. Manusia yang menentukan teknologi akan seperti apa atau bermanfaat untuk apa. Inilah yang disebut konstruksi sosial terhadap teknologi.

Pinch dan Bijker mengonsepkan Teori Konstruksi Sosial Teknologi yang bermula dari sepeda. Awal mula teknologi dan desain sepeda ditujukan kepada lelaki. Konstruksi sepeda itu pun kemudian mengalami perubahan ketika kaum wanita ingin juga bersepeda. Hal itu terjadi seiring gencarnya gerakan feminisme. Sehingga melahirkan sepeda yang secara desain ditujukan untuk wanita. Perubahan konsep desain sepeda adalah bentuk konstruksi suatu teknologi.

Di zaman modern, transaksi tidak lagi mengharuskan Anda memakai uang tunai. Sekarang, Anda dapat menggunakan sebuah aplikasi mobile, mengandalkan data akses internet saat bertransaksi. Ini adalah metode mobile payment, mari kita kenali beberapa manfaat yang akan Anda rasakan.

\section{- Kecepatan Transaksi}

Kecepatan transaksi sangatlah penting, terlebih jika Anda berbelanja online yang mengharuskan Anda lebih cepat menyelesaikan pembayaran. Dengan mobile payment, Anda tak perlu lagi menginput data kartu debit dan kredit sehingga membuat proses jauh lebih cepat. Untuk prosesnya sendiri, Anda hanya perlu scanning QR code smartphone saat melakukan pembayaran.

\section{- Fleksibel}

Membayar uang tunai saat bepergian ada kalanya cukup merepotkan. Dengan berbelanja dan bertransaksi menggunakan aplikasi mobile payment, Anda akan menghilangkan kerepotan ini, karena transaksi dapat dilakukan dengan smartphone, tanpa melibatkan uang tunai. Hanya dengan hitungan detik saja, transaksi Anda dapat diselesaikan, membuat waktu jauh lebih singkat. 


\section{- Kontrol Pengeluaran}

Anda yang konsumtif dan malas mencatat pengeluaran tentu saja pernah menghabiskan uang tunai, sehingga terpaksa menggunakan kartu debit dan kredit untuk membayar transaksi yang diluar dari anggaran. Tetapi, hal ini dapat Anda hindari, dimana mobile payment dapat mengontrol anggaran belanja Anda.

Anda hanya memakai dana sesuai sisa saldo. Selain untuk Anda, mobile payment pun efektif digunakan oleh asisten rumah tangga ataupun keluarga Anda, dimana pengeluaran untuk belanja, makan dan sebagainya dapat lebih mudah untuk Anda kontrol.

\section{- Promo Menguntungkan}

Kebebasan keuangan saat ini sedang gencar dipromosikan. Melalui hal ini, ada keuntungan lain yang akan Anda dapatkan, dimana berbagai merchant berlomba menawarkan promosi yang dapat dimanfaatkan oleh Anda. Disamping itu, Anda pun dapat memilih aplikasi pembayaran yang memberikan sejumlah poin setiap bertransaksi, dimana poin tersebut dapat Anda manfaatkan untuk ditukar dengan hadiah menarik.

Kecepatan transaksi, fleksibilitas, penghematan budget dan promo menguntungkan merupakan bagian kecil dari manfaat yang Anda rasakan melalui transaksi dengan mobile payment. Tunggu apalagi, segera tinggalkan cara lama Anda berbelanja dan bayar dengan aplikasi mobile payment.

Sebagaimana yang telah diungkapkan dalam buku Media Now (edisi 7), ada tiga tipikal orang dalam pemanfaatan teknologi. Kategori pertama adalah orang yang mengikuti trend, ini disebut sebagai pembentuk awal agar menjadi mayoritas sebuah teknologi. Kelas kedua adalah orang yang hanya melihat sesuatu yang dibuat, ia disebut sebagai pengikut. Ia bisa berubah karena mungkin organisasi lingkungan orang tersebut hidup mengharuskannya memanfaatkan teknologi baru. Sehingga akhirnya ia pun memanfaatkan sebagai sebuah keharusan. Sedang tipikal ketiga yaitu orang yang hanya menunggu dan disebut sebagai tertinggal. Tipikal ini adalah orang yang sudah tidak punya pilihan. Ia masuk di dalam kebaruan teknologi tanpa sebuah pilihan. Karena majoritas sudah memanfaatkan teknologi baru.

Pemanfaatan teknologi ini sangat bergantung pula dengan budaya (culture) si pelaku 
proses komunikasi. Teknologi terbentuk untuk menyesuaikan kebutuhan manusia akan kegiatan melakukan pembayaran secara aman dan mudah serta fleksibel dari telefon atau ponsel konsumen.

\section{Prediksi Mengenai Mobile Payment}

Berbagai riset seperti IDC (International Data Corperation) dan Ipsos Mori (lembaga riset besar di Inggris), telah menyoroti mengenai perkembangan mobile payment yang akan terjadi beberapa tahun mendatang. IDC melakukan riset mengenai adopsi mobile payment yang terjadi di Asia Pasifik, dan Ipsos Muri melakukan penyebaran kuisioner untuk beberapa orang di negara Inggris.

Jika Indonesia menginginkan lonjakan mobile payment, perusahaan dan negara harus terus melakukan sosialisasi mengenai apa yang diragukan masyarakat. Salah satu isu yang harus diluruskan mengenai keamanan yang digunakan mobile payment. Tidak hanya itu salah satu cara agar mobile Payment di Indonesia mendapakan lonjakan, mobile payment yang dibuat harus benar-benar dibutuhkan oleh target pasarnya.

Berdasarkan perkembangan teknologi sekarang, memungkinkan untuk melakukan transaksi dengan berbagai metode. Transaksi pembayaran mungkin akan lebih mudah dengan keamanan yang lebih bagus dari sekarang. Memang bisa saja terjadi karena semakin majunya teknologi sekarang ini, dan sudah mulai banyak bermunculan pembayaran elektronik ini sangat memungkinkan 5 tahun atau 10 tahun yang akan datang karena untuk lebih memudahkan kita tentunya dalam hal bertransaksi melaui mobile payment.

\section{Kesimpulan}

Dari semua teori ini dapat diambil kesimpulan bahwa komunikasi adalah bagian dari kebutuhan manusia sebagai makhluk sosial dan diri sendiri. Proses penyampaian pesan bisa dengan memanfaatkan teknologi sangat bergantung kepada pengalaman dan behaviour orang. Komunikasi tetaplah sebuah proses simbol to symbol. Pemanfaatan teknologi ini sangat bergantung pula dengan budaya (culture) si pelaku proses komunikasi.

Komunikasi adalah sebuah konstruksi sosial. komunikasi terbangun dalam sebuah sistem yang saling berkaitan satu sama lain. Teknologi media yang terus berkembang sejalan dengan industri adalah merupakan stimulant atau alat bagi proses komunikasi. Ada nilai interpelasi dan entertainment (kepuasan) di setiap pemanfaatan teknologi. Teknologi tidak 
akan bisa berdiri sendiri. Teknologi akan sangat bergantung kepada manusia, budaya dan organisasi.

\section{Daftar pustaka}

Artkel Akhmad Mulyadi : Bisnis online, pulsa, komputer dan internet 2009

Jurnal David McKitterick and Jim DowlingState of the Art Review of Mobile Payment Technology (2003)

Kungpisdan, S., 2005, Modelling, Design, and Analysis of Secure Mobile Payment Systems, Disertasi, Faculty of Information Technology Monash University, Melbourne.

Understanding Media: The Extensions Of Man (eBook Edition) by Marshall McLuhan

Gingko Press (2013)

Wu, H., Li, X., Dai, W., Zhao, W., 2010, Mobile Payment Framework Based on 3G, Proceedings of the Third International Symposium on Electronic Commerce and Security Workshops (ISECS '10), Guangzhou, 29-31,July 2010.

www.bersosial.com (diakses10 April 2016, pukul 13.25 WIB)

Copy the BEST Traders and Make Money : http://ow.ly/KNICZ (Diakses pada 10 April 2015, pukul 12.30 WIB)

http://ide-informatika.blogspot.co.id/2012/05/e-payment.html (Diakses 11 April 2016, pukul 19.40 WIB) 